\title{
Reinforcement delay: A parametric study of effects within a multiple schedule
}

\author{
RALPH W. RICHARDS and W. M. HITTESDORF \\ Colorado State University, Fort Collins, Colorado 80523
}

\begin{abstract}
Independent groups of pigeons received different durations of reinforcement delay $(0,2.5,5,10$, or 20 sec) during the second component of a multiple variable-interval 1-min variable-interval 1-min schedule of reinforcement; all birds received immediate reinforcement during the first component. In general, response rates during the delayed reinforcement component decreased as the duration of reinforcement delay was increased. Groups that received 5-, 10-, and 20-sec durations of reinforcement delay responded at a higher rate during the immediate reinforcement component than the groups that received 0 - and 2.5-sec durations of reinforcement delay. A subsequent generalization test showed clear differences between the groups, with stronger and more consistent inhibitory control being exerted by the stimulus associated with a 20 -sec duration of reinforcement delay.
\end{abstract}

In a two-component multiple schedule, an organism is successively presented with two stimuli, each of which is associated with an independent schedule of reinforcement. Much of the interest in multiple schedules has been in terms of the nature of control exerted by the stimuli associated with each of the components. When the training stimuli lie on orthogonal stimulus dimensions, it is possible to independently measure the control exerted by each stimulus by testing for generalization along each dimension. An inverted U-shaped gradient, the peak of which occurs at one of the training stimuli, is generally taken to define excitatory stimulus control (e.g., Terrace, 1966), and several investigators (e.g., Jenkins, 1965, Terrace, 1966, 1972) have suggested that a U-shaped gradient, the nadir of which occurs at one of the training stimuli, defines inhibitory stimulus control.

Several recent studies (Richards, 1973, 1974) have obtained a U-shaped gradient around the stimulus associated with the second component of a multiple variable-interval 1 -min variable-interval 1 -min schedule when reinforcement was delayed for $10 \mathrm{sec}$ during the second component. In the present study, the duration by which reinforcement was delayed during the second component of such a multiple schedule was parametrically examined. Although the primary concern was the nature of the subsequently obtained generalization gradients, response rates in the components of the multiple schedule were also examined.

\section{METHOD}

\section{Subjects}

Fifty-seven experimentally naive adult female White Carneaux pigeons were maintained at approximately $80 \%$ of their free-feeding weights.

A version of this paper was presented at the 1975 meeting of the Psychonomic Society.

\section{Apparatus}

A slide projector, mounted behind the center key of a standard operant conditioning chamber, was used to project the training stimuli ( $\mathrm{S} 1$, a homogeneous white light; $\mathrm{S} 2$, a vertical black line on a white surround) and the generalization test stimuli (S1, S2, and the black line with departures of +30 , $+60,-30,-60$, and $\pm 90 \mathrm{deg}$ from $\mathrm{S} 2$ on a white surround). All lines were approximately $1 / 16$ in. thick. Overall illumination of the chamber was provided by the standard houselight and two pilot lights that were mounted slightly above the two covered side keys. A green pilot light was mounted on the chamber's back wall.

\section{Procedure}

After the keypeck was shaped, the duration of reinforcement (access to mixed grain) was maintained at $1.5 \mathrm{sec}$. The timing of the reinforcement cycle was controlled by a photocell located within the food aperture. One-second blackouts (during which responding was nonfunctional) were subsequently inserted between successive 30 -sec stimulus presentations; this 30 -sec duration was exclusive of reinforcement time and the periods of time-out and reinforcement delay that were subsequently introduced. The response requirement was gradually increased until a fixed-ratio 20 schedule was attained, and all subjects then received five sessions (48 stimulus presentations per session) of reinforcement according to a variableinterval 1-min schedule.

On completion of preliminary training, during which only S1 had been presented, subjects were assigned to one of the following six groups: time-out, 0 -sec, $2.5-\mathrm{sec}, 5-\mathrm{sec}, 10-\mathrm{sec}$, or 20 -sec. Assignment was conducted so that the groups' mean response rates during the last session of preliminary training were approximately equal. There were seven subjects in the time-out group and 10 subjects in each of the remaining groups. All subjects then received 18 sessions ( 48 stimulus presentations per session) of reinforcement according to a multiple variableinterval 1-min variable-interval 1-min schedule. Throughout training, S1 (during which reinforcement was not delayed) and S2 were presented in mixed order. During S2, reinforcement was delayed for subjects in the 2.5-, 5-, 10-, and 20-sec groups (the group designation specifies the duration of reinforcement delay). During the delay periods, only the green pilot light on the chamber's back wall was illuminated. The subjects in the 0 -sec and time-out groups received immediate reinforcement during the S2 component; responding of subjects in the time-out group also produced 20 -sec time-outs during S2 


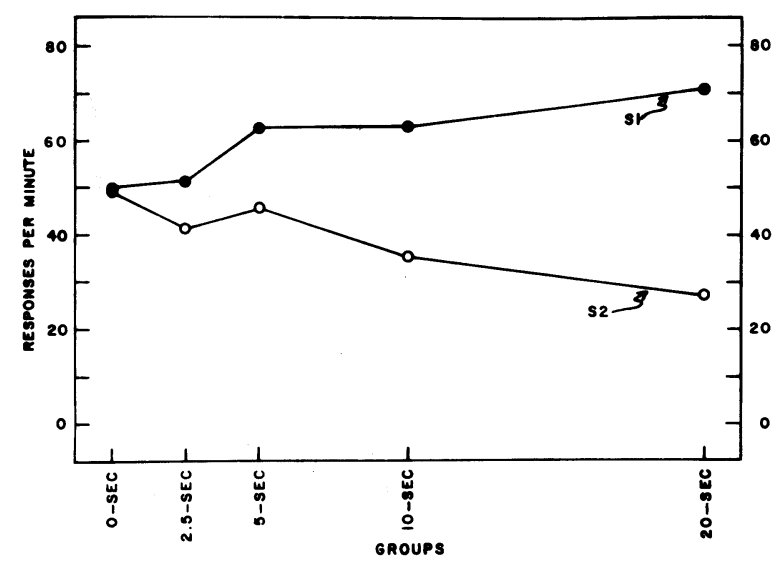

Figure 1. Mean response rates to $S 1$ and $S 2$ during the last session of multiple schedule training.

according to an independent variable-interval 1-min schedule. During time-out, only the green pilot light on the chamber's back wall was illuminated. The time-out group was a control group from which to evaluate any unconditional effects of the green pilot light's illumination. Responding during timeout and delay periods was nonfunctional. To assure that each subject in the delayed reinforcement groups received an approximately equal number of reinforcements during $S 1$ and S2, the S2 tape timer continued to "run" after a reinforcement was "set up" and continued until, as occasionally occurred, a second reinforcement was "set up;" in a few instances, the experimenter "erased" and/or "set up" reinforcements (timeouts) during a component.

The session following completion of multiple schedule training began with a brief period of additional training (16 stimulus presentations) and ended with a test for generalization that was conducted during extinction. Each of the seven generalization test stimuli was presented in random order within each of six blocks. As in training, 30-sec stimulus presentations were separated by $1-\mathrm{sec}$ blackouts.

\section{RESULTS}

Figure 1 shows the mean rate of response of each group $^{1}$ to $S 1$ and $S 2$ on the last day of training. In general, as the duration of reinforcement delay in S2 was increased, the $\mathrm{S} 2$ response rates decreased and the S1 response rates increased. After separate analyses of variance yielded a significant effect for $\mathrm{S} 2$ response rates $(F=5.21$, df $=4 / 45, p<.005)$ and a nearly significant effect for $S 1$ response rates $(F=2.34$, $\mathrm{df}=4 / 45, \mathrm{p}<.07$ ), Bonferroni $\mathrm{t}$ tests (Wike, 1971, pp. 72-73) were conducted and the following comparisons were found significant $(p<.05)$ : $S 2$ response rates-all possible combinations, except 2.5 -sec vs. 5 -sec, $2.5 \mathrm{sec}$ vs. 10 -sec, and 0 -sec vs. 5 -sec; $\mathrm{S} 1$ response rates5 -sec vs. 0 -sec, $10-\mathrm{sec}$ vs. $0-\mathrm{sec}, 20-\mathrm{sec}$ vs. $0-\mathrm{sec}, 5-\mathrm{sec}$ vs. 2.5 -sec, 10 -sec vs. 2.5 -sec, and $20-\mathrm{sec}$ vs. 2.5 -sec. While the individual subjects in the 0 -sec group did not show a consistently higher rate of response to $S 1$ or $S 2$, seven subjects in both the $2.5-\mathrm{sec}$ and 5 -sec groups responded at a rate of at least five responses per min higher to $S 1$ than S2. Nine subjects in the 10-sec group and all subjects in the 20 -sec group responded at a substantially higher rate to $\mathrm{S} 1$ than $\mathrm{S} 2$.

Relative generalization gradients for the individual subjects are presented in Figure 2; the dependent variable in this figure is the number of responses to the test stimulus divided by the number of responses to S2 during the generalization test. The open circle in each panel indicates S2 (the 0-deg line); the smaller closed circles to the right (left) of S2 indicate the $+30-$, +60-, and +90-deg (-30-, -60-, and -90-deg) lines. While several subjects in the 0 -sec, $2.5-\mathrm{sec}, 5-\mathrm{sec}$, and $10-\mathrm{sec}$ groups showed a U-shaped gradient, only the 20 -sec delay was unequivocal in its production of such gradients. Many of the U-shaped gradients, across all groups, showed a "shoulder(s) effect," with the +60-deg and/or -60-deg line generating more responses than the \pm 90 -deg line. Since subjects in the time-out group did not show U-shaped gradients, the U-shaped gradient in the delay groups cannot be attributed to the delay signal per se. Because of the large within-group differences in the qualitative nature of control exerted by $\mathrm{S} 2$, no statistical comparisons between the mean gradients of the groups are reported.

\section{DISCUSSION}

In the present study, the rate of response during the delay component decreased as the duration of reinforcement delay increased. This inverse relationship between the duration of reinforcement delay and response rate is consistent with many previous findings (see review by Renner, 1964). Groups that received 5-, 10-, and 20-sec durations of reinforcement delay during S2 also showed behavioral contrast, as evidenced by their significantly higher rates of responding during S1, compared to the group that received immediate reinforcement during S2. This latter finding is in agreement with several previous within-subject demonstrations of delay-induced behavioral contrast (e.g., Richards, 1972; Wilkie, 1971).

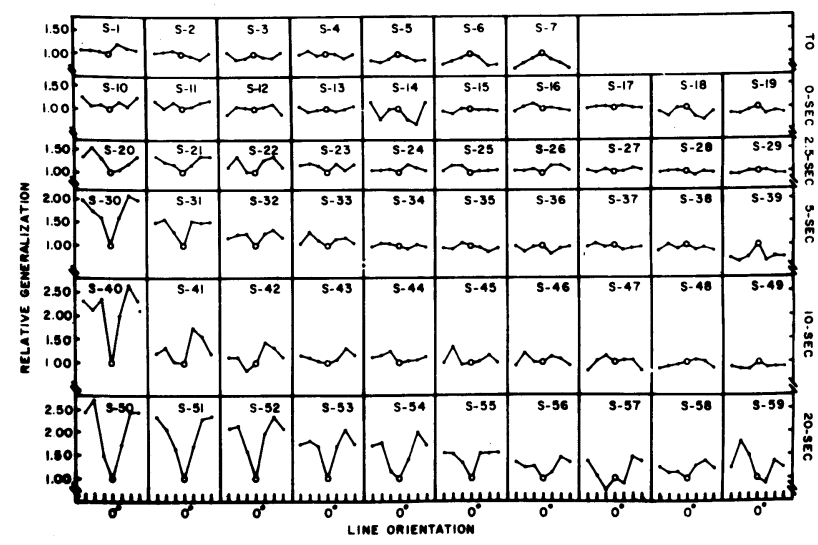

Figure 2. Relative generalization gradients for each bird. The group designation is indicated at the end of each row. The dependent variable is the number of responses to the test stimulus divided by the number of responses to $S 2$ during the generalization test. The open circle in each panel indicates S2 (the 0-deg line); the smaller closed circles to the right (left) of S2 indicate the +30 , +60 , and $+90-\mathrm{deg}(-30-,-60-$, and -90-deg) lines. 
In terms of stimulus control, S2 was more likely to exert inhibitory control for subjects that received delayed reinforcement during $\mathrm{S} 2$. However, inhibitory control by S2 was consistently obtained in only the 20 -sec delay group. The large withingroup variability in the qualitative nature of the stimulus control exerted by S2 in the 2.5-, 5-, and 10-sec delay groups was unexpected. This variability was especially surprising in the last group, since U-shaped gradients were relatively consistently obtained in previous research with this delay duration (Richards, 1973, 1974). Although any of several procedural differences between the studies may be responsible for the large variability in the present study's gradients, a likely possibility is the absence of time-outs in the S1 components of the present study. In previous research, any possible unconditional effects of the delay signal were controlled for by delivering response-dependent time-outs during $\mathrm{S} 1$; the temporal and physical characteristics of the time-out and delay signal were identical. ${ }^{2}$ As S1 time-outs were not followed by reinforcement, the previous studies' procedure may have reduced any conditioned reinforcing value that the delay signal could have acquired. When S1 time-outs were not delivered in the present study, the delay signal may have become an effective conditioned reinforcer that reduced the inhibitory aspects of reinforcement delay. This suggestion is, of course, amenable to experimental investigation.

Irrespective of the above, it is, of course, possible that more extended multiple schedule training may have reduced the variability. Results of the computation of a post hoc correlation between (a) the difference in response rates to $\mathrm{S} 1$ and $\mathrm{S} 2$ at the end of training and (b) the percentage of the total responses emitted to S2 during the generalization test (exclusive of the responses to S1) support the suggested importance of amount of training. (The percentage of responses to $S 2$ provides a crude estimate of the degree of stimulus control exerted by $\mathrm{S2}$.) Combining all subjects, the correlation coefficient was -.703 ( $\mathrm{p}<.001$ ) and, considering the time-out, 5-sec, and 10-sec groups separately, the coefficients were $-.795,-.708$, and -.676 (ps $<.05$ ), respectively. Since the degree of differential responding might reasonably have been expected to increase with more extended training, the degree of inhibitory stimulus control might also have increased. It is instructive to note that Wheatly and Thomas (1974) recently reported a strong positive correlation between the degree of differential responding at the end of training on various multiple schedules and the occurrence of the peak shift phenomenon. Several investigators (e.g., Hearst, 1968; Terrace, 1966; Thomas \& Williams, 1963; Weisman, 1969) have, of course, suggested a close relationship between the peak shift and the inhibitory gradient.

\section{REFERENCES}

Hearst, E. Discrimination learning as the summation of excitation and inhibition. Science, 1968, 162, 1303-1306.
Jenkins, H. M. Generalization gradients and the concept of inhibition. In D. I. Mostofsky (Ed.), Stimulus generalization. Stanford: Stanford University Press, 1965. Pp. 55-61.

Renner, K. E. Delay of reinforcement: A historical review. Psychological Bulletin, 1964, 61, 341-361.

RICHARDs, R. W. Reinforcement delay: Some effects on behavioral contrast. Journal of the Experimental Analysis of Behavior. $1972,17,381.394$.

RICHARDS, R. W. Stimulus generalization and delay of reinforcement during one component of a multiple schedule. Journal of the Experimental Analysis of Behavior, 1973, 19, 303-309.

RichaRDs, R. W. Inhibitory stimulus control and the magnitude of delayed reinforcement. Journal of the Experimental Analysis of Behavior, 1974, 21, 501-509.

Terrace, H. S. Stimulus control. In W. K. Honig (Ed.), Operant behavior: Areas of research and application. New York: Appleton-Century-Crofts, 1966. Pp. 271-344.

TERRACE, H. S. Conditioned inhibition in successive discrimination learning. In R. A. Boakes and M. S. Halliday (Eds.), Inhibition and learning. London: Academic Press, 1972. Pp. 99-119.

Thomas, D. R., \& Williams, J. L. A further study of stimulus generalization following three-stimulus discrimination training. Journal of the Experimental Analysis of Behavior, 1963 . 6. 171-176.

WEISMAN, R. G. Some determinants of inhibitory stimulus control. Journal of the Experimental Analysis of Behavior, 1969 , 12. 443-450.

Wheatley, K. L., \& Thomas, D. R. Relative and absolute density of reinforcement as factors influencing the peak shift. Journal of the Experimental Analysis of Behavior, 1974, 22, 409-418.

Wike, E. L. Data analysis. Chicago: Aldine-Atherton, 1971. WILKIE, D. M. Delayed reinforcement in a multiple schedule. Journal of the Experimental Analysis of Behavior, 1971, 16. 233-239.

\section{NOTES}

1. There was no statistically significant difference between $\mathrm{S} 1$ and $\mathrm{S} 2$ response rates in either the 0 -sec or time-out groups, nor did these groups differ significantly from each other. Because of the latter finding, no further mention will be made of the time-out group's response rates, since this group was only included to assess any possible unconditional effects of the signal associated with the delay period.

2. The present study's time-out group showed that there was no unconditional effect of the delay signal per se, when it was not followed by food reinforcement.

(Received for publication November 17, 1975.) 